case of morbilli at a period when catarrh is quite incipient ; and the only reliable means of doing this which we at present possess is by means of these spots of Filatow's. Of the value of this method of eradicating morbilli from wards I can speak from personal experience, and in the case of schools I would suggest that when at any time it is found necessary to stamp out an epidemic, a daily examination for these spots in the mouths of all the scholars should be carried out in a good window-light, since it is an examination that can be very readily performed, and is the only method at our command which offers any decided hopes of proving effectual.

Bibliography.-1880, Flindt: Sundhedskollegiets Aarsbaretning. 1895, Jürgensen : Nothnagel's Specielle Pathologie und Therapie, Acute Nxantheme, Masern, p. 92. 1895, Filatow : Acute Infections-Krankheiten, p. 349, third Russian edition. 1896, Koplik: Archives of Pediatrics, p. 918. 1898, Koplik : Medical Record, April 9th, 1898. 1898, Slawvk: Deutsche Medicinische Wochenschrift, No. 17. Libman : Medical Record, June 11th, 1898. Finkelstein : Berliner Klinische Wochenschrift, July 4th, 1898. Kuöspel: Prager Medicinische Wochensohrift, 1898, No. 41 and No. 42. Sobel : New York Medical Journal, 1898, p. 558. Weiss: Wiener Klinische Wochenschrift, 1899, No. 26. Rolly : Münchener Medicinische Wochenschrift, 1899, No.38. Maroney : Yale Medical Journal, October, 1900.

Laugharne, Carmarthenshire.

\section{LAPAROTOMY AND CLEANSING OF THE PERITONEUM IN A CASE OF TUBER- CULOUS PERITONITIS.}

By GEORGE WILliaM DAVIS, M.D., B.S. DuRH., L.R.C.P. LOND., M.R.C.S. ENG.

ON Feb. 27th, 1900, I was called to visit a girl, aged seven years, who was too ill to continue her visits to the physician in town to whom she bad previously been taken. I was told that she was suffering from "catarrh of the stomach."

The condition of the patient was as follows:-The abdomen was very tympanitic and resonant throughout. No fluid could be discovered. Apparently continuous with the edge of the liver was a mass which appeared to be a solid tumour within the abdomen; it extended in the line of the gall-bladder from the liver edge downwards to one and a half inches below the umbilicus, and then was continued across the abdomen to the opposite ribs at the same level, its margin being marked with four large sinuosities. The mass was smooth, resistant to the touch, and it could be grasped at the lower margin by the fingers, giving an impression of a solid tumourous mass. The skin over it was free and no movement in a vertical direction occurred in respiration. Percussion gave resonance over the whole area which was occupied by the mass. Two enlarged glands could be felt in the left iliac fossa. No signs of disease could be discovered in any other organ. There was occasional vomiting which would occur every third day or so. There was a good deal of flatulence and constipation and the stools were greenish and flocculent; they contained much mucus and were very offensive.

With regard to treatment, as the child's temperature registered nightly from $101^{\circ}$ to $102^{\circ} \mathrm{F}$. she was kept in bed and her bedroom was kept warmed and freely ventilated; she was given such light foods as bread jelly, yelk of egg, rusks, bread-and-milk, meat broths, meat juice, \&c. ; passive movements of the limbs with massage were performed daily; and castor oil in frequently repeated small doses was given for the constipation, with an occasional enema. The child improved to a certain extent. Many of her symptoms appeared to mend; she became less irritable and slept rather better, the sickness ceased, and the stools improved in appearance. It was, however, difficult to measure improvement in these matters and the measurable symptom, the temperature, showed a gradual average rise by the end of April. The outline of the tumour showed an advance in size to the extent of half an inch in two months. I therefore advised an exploratory laparotomy. The following was the average temperature for the five months :-March, morning, $976^{\circ}$; evening, 100.3 $3^{\circ}$ April, morning, $99.5^{\circ}$; evening, $101.5^{\circ}$. May (operation on the 2nd), morning (?); evening, $99 \cdot 3^{\circ}$. June, morning, $98.8^{\circ}$; evening, 99.6. July, morning, $988^{\circ}$; evening, $98.9^{\circ}$.

On May 2nd chloroform was administered by Dr. James
Crombie, and, assisted by Dr. R. R. Law and by Mr. E. C. Stabb, whose kind offer to be present was gladly accepted, the abdomen was opened in the middle line for three inches immediately below the edge of the bard mass referred to above. Some sero-puriform fluid escaped. Digital exploration through the wound discovered extensive but weak adhesions, which were firmest towards the rim of the pelvis but were easily broken down. The tumour-like mass in the upper abdomen appeared to the fingers as a shield of tissue of an even thickness of three-quarters of an inch; it was smooth and resistant and was closely incorporated with the abdominal wall. The impression conveyed to the touch was that of a fibrous structure and it was doubtless a fibrous areola which had originated in the peritonitic inflammation excited in the neighbourhood of tuberculuns nodules which would thus be included by the meshes of the inflammatory tissue. The peritoneum was every where studded with nodules and one of these was removed for examination from the serous covering of the ileum. The adhesions having been broken down the peritoneal cavity was thoroughly douched out with two gallons of normal saline solution by means of a Spencer Wells large-bore douching cannula, which was carried down with the finger as a guide into the pelvis and into every part of the abdominal cavity. A careful toilet with sponges on holders terminated the operation, and the wound was brought together in its deeper parts by buried sutures of fine silkworm gut and by ordinary silkworm gut for the skin.

The after progress of the case was quite uneventful. On the evening of the operation the temperature rose to $102 \cdot 6^{\circ}$ and from that time it was slick tly subnormal for 10 days, after which it rose to $98.8^{\circ}$ or $99.4^{\circ}$, at which it has remained since. The following is the report of the Clinical Research Association on the nodule removed: "This nodule shows groups of grey and caseous tubercles embedded in much young inflammatory tissue on the peritoneum. The giant cells are large and numerous."

Eight months have now elapsed since the operation, daring which time every endeavour bas been made to improve the condition of the child. Exercises after the manner of $\mathrm{Mr}$. Bernard Roth have been employed daily; during the whole summer the child bas lived an open-air existence and other rational measures have been employed, while good nourishing solid food has been given, with as much scalded cream as the child could take. The condition of the patient is such as to make the prognosis very hopeful concerning her ultimate recovery, providing one is given a free hand to interfere surgically as of ten as indication arises. The physical condition of the abdomen has in these five months become modified. The mass which formerly occupied a continuous area as described is now represented by a margin of the original mass next against the liver edge and by scattered masses mapped over the area previously occupied by the shield-like neoplasm. There are yet glands to be felt in both iliac fossæ, but their much greater size leads me to think, in the absence of temperature, that they are probably ensheathed in fibrous tissue. There is a small tuberculous nodule in the fold of the right buttock which has been present since April and which involves the skin. The general appearance of the child has quite altered. From being somewhat wizened and prematurely wise in face, action, and manner, she has plumped up and has become naturally mischievous and romping as a child should be.

In these cases delays have a dangerous end. There is unquestionably a more pronounced progression in gravity between serous and suppurative peritonitis than between serous pleuritis and empyema. Once the effused fluid has become puriform the prognosis as to recovery from operation must be quite a different matter from that of the eame case in the serous stage, for the suppurative peritonitis includes a long history-firm adhesions, encysted pus, limited by anatomical boundaries whose resistance is lessened by the continued inflammatory processes, make up together a posse of difficulties not to be encountered with a light beart. To all surgeons accustomed to perform abdominal sections there can surely be no more disheartening condition than these lacunæ with washleather-like sloughy walls containing stinking acrid pus which in many cases are so numerous and so hidden by more superficial adbesions that the main difficulty lies in being sure that all such encystments have been exposed and cleansed. It appears to me that, given the presence of tuberculouslike masses in the abdomen and a nightly rise of temperature not mitigated by treatment and continuing for an entire month, the time has arrived for an 
exploratory laparotomy; and there appears to be no reason why such an operation should not be repeated as often as similar indications arise providing that the general condition of the patient is such as would enconrage a good prognosis. Sidcup.

\section{SELENIUM COMPOUNDS AS FACTORS IN THE RECENT BEER-POISONING EPIDEMIC.}

BY F. W. TUNNICLIFFE, M.D., M.R.C.P. LOND., PROFESSOR OF MATKRIA MEDIOA AND PHARMACOLOGY IN KING's GOLT.FGR, LONDON : AND

OTTO ROSENHeIM, Ph.D., F.C.S.

ALTHovar no doubt we may in the immediate future be in possession of a more copious literature on the most interesting recent beer-poisoning epidemic it cannot be denied that at the present time, thanks to the energy of the various workers in this field, we have at our command a very adequate material upon which to base conclusions and criticisms. Upon reviewing especially Kelynack's and Kirkby's book and Reynolds's paper on this subject we were struck, as probably many others have been, with the apparent incongruity between the doses of arsenic taken and the effects produced. Although in some cases the amonnt of arsenic found in the beer and actually consumed by the patient is unquestionably sufficient to explain the poisoning, in other instances this is by no means clear.

In trying to explain this anomaly four principal alternatives suggest themselves. The first one obviously is to assume a want of accuracy in the results of the quantitative analyses. We must regard all the methods at present employed for the estimation of those very small quantities of arsenic in complex liquids like beer as only capable of giving approximately accurate results. On the whole, however, the results obtained in this connexion err probably in the direction of the maximum rather than in that of the minimum, and we are inclined, therefore, to disregard error in quantitative analysis as an explanation.

It has been further suggested that the arsenic may be present in some organic (biological) combination formed by the action of certain micro-organisms during fermentation; in support of this the work of Gosio and others has been adduced with regard to the power of certain organisms (especially penicillium brevicaule) to form organic gaseous substances from minute traces of solid arsenic compounds. A part from the fact that these micro-organisms have never been found to exist in the presence of active yeast, it is very unlikely that their products would remain unnoticed in the finished beer, as it is precisely their characteristic smell which serves for their detection in the more minute quantities.

A third series of explanations are characterised by one common feature-viz., their absolute vagueness. They all assume the presence of poisonous by-products of unknown nature formed by the action of pure or arsenicated sulphuric acid during the manufacture of the brewing sugars or during the fermentation of these sugars. No poisonous substance of this class has, however, been isolated and their existence must be regarded as purely hypothetical.

The fourth explanation, and the one adopted by us, is that some tangible poisonous substance which has up to the present escaped detection and estimation has found its way into the beer along with the arsenic. In searching for such a substance we directed our attention to the possible impurities of sulphuric acid other than, but exerting a physiological action similar to, arsenic. Selenium and thallium at once suggested themselves to us.

It is a known fact that selenium occurs together with arsenic in nearly all pyrites and the sulphnric acids prepared from them. ${ }^{1}$ It has also lately been pointed out that the present technical operations for the removal of arsenic do not render the acid selenium free.2 We were able to convince ourselves that even colourless commercially purified English sulphuric acid still contained selenium and that the dark brown commercial "double rectified oil of vitiol"

1 Personne, Lamy, Scheurer-Kestner: Comptes Rendus, 1872 ; Drinkwater : Analyst, viii,

water: Analyst, viii.
S Schlagdenhauffen and Pagel: Journal de Pharmacie et de Chimie, 1900 .
(D.O.V. or R.O.V.) as sent out by the chemical manufacturer implicsted in the recent poisonous cases, and therefore probably identical with that alleged to have been ordered by the sugar manufacturers, gave a very strong selenium (and arsenic) reaction. Upon quantitative estimation this latter acid yielded 0.2 per cent. of selenium or 0.3 per cent. selenious acid. We have up to the present been unable to obtain the ordinary "brown oil of vitriol" (B.O.V.) which was actually used in the manufacture of the sugar and which, according to the published analysis, contained about 1.4 per cent. of arsenious acid. It is obviously to be inferred that the percentage of selenium in this latter acid is raised accordingly.

The chemical properties of selenium and selenious acid render it practically certain that they would pass over together with the arsenic into the sugur manufactured by means of the impure sulphuric acid and thus be present in the corresponding beer.

If we now consider selenium compounds from a pharmacolegical standpoint we find that they are highly poisonous, and although chemically allied to sulphur compounds are in their physiological behaviour practically identical with arsenic. So similar are the effects produced by these two poisons that according to Kobert ${ }^{3}$ the one may be easily mistaken for the other. According to C. Chabrié ${ }^{*} 0003$ grammes per kilo body weight is lethal for dogs. No cases of selenium poisoning have so far been recorded in man, but the general symptoms in animals are identical with those produced by arsenic. 5

With regard to the detection of selenium we would draw attention to the following points. It is precipitated along with arsenic in Reinsch's test and may be mistaken for arsenic before sublimation. When not specially looked for it may escape detection in the presence of arsenic even after sublimation. ${ }^{6}$ By Gutzeit's or Marsh's test for arsenic it is not shown, being precipitated by the zinc and sulphuric acid. A very sensitive reagent for it in colourless sulphuric acid is codeine, with which it gives, in the cold, a green colour, changing to steel blue at warm bath temperature.

From the above considerations we regard the conclusion justified that selenium compounds have played a definite rôle in the recent beer-poisoning epidemic. Their part, however, is subsidiary to that of arsenic. The presence of selenium in the beer would explain many anomalous cases, amongst which may be numbered those in which the dose of arsenic taken was very small, those in which arsenic could not be found in the excretion, and those also (notably two cases of infants at the breast) in which no arsenic could be found in the milk. In the absence of extensive pharmacological investigation upon the higher animals it is impossible to say to what extent the presence of selenium with the arsenic might modify the symptom complex produced by this latter poison.

The most important conclusion, however, which we would draw from our investigations relates not to the past but to the future. In view of the poisonons action of selenium it is absolutely essential that all sulphuric acids used in the manufacture of food products should not only be arsenic but also selenium free.

King's College, London.

\section{AN INTRA-PERITONEAL METHOD FOR RADICAL CURE OF INGUINAL HERNIA.}

BY T. H. WELLS, M.D. LoND., M.R.C.S. ENG., TATE AOTING HOUSE SURGEON TO RADCLIFFE INFIRMARY, OXFORD.

HAVING seen the following operation performed by Mr. Symonds with great ease and celerity and with marked ultimate success, it seemed that a short description of the operation as carried out by him might be interesting and instructive. The danger of opening the peritoneal cavity

\section{Lehrbuch der Intoxicat., 1893, p. 382.}

4 Annales Chin

vol. cx., p. 152 P. 1898. p. 221 .

6 If selenium and arsenium are precipitated together upon copper foil as in Reinsch's test and carefully sublimated, in addition to the well-characterised erystals of arsenic, fern- or feather-shaped crystals of selemious acid can be distingu
identified by various methods. 